\title{
Forecasting wind power production from a wind farm using the RAMS model
}

\author{
L. Tiriolo ${ }^{1}$, R. C. Torcasio $^{1}$, S. Montesanti ${ }^{1}$, A. M. Sempreviva ${ }^{2}$, C. R. Calidonna ${ }^{1}$, C. Transerici $^{3}$, and \\ S. Federico ${ }^{3}$ \\ ${ }^{1}$ Institute of Atmospheric Sciences and Climate of the Italian National Council of Research, ISAC-CNR, UOS \\ of Lamezia Terme, zona Industriale Comparto 15, 88046 Lamezia Terme, Italy \\ ${ }^{2}$ Wind Energy Department, Danish Technical University, Frederiksborgvej 399, 4000-Roskilde, Denmark \\ ${ }^{3}$ ISAC-CNR, UOS of Rome, via del Fosso del Cavaliere 100, 00133-Rome, Italy
}

Correspondence to: L. Tiriolo (1.tiriolo@isac.cnr.it)

Received: 8 January 2015 - Revised: 26 March 2015 - Accepted: 27 March 2015 - Published: 9 April 2015

\begin{abstract}
The importance of wind power forecast is commonly recognized because it represents a useful tool for grid integration and facilitates the energy trading.

This work considers an example of power forecast for a wind farm in the Apennines in Central Italy. The orography around the site is complex and the horizontal resolution of the wind forecast has an important role.

To explore this point we compared the performance of two $48 \mathrm{~h}$ wind power forecasts using the winds predicted by the Regional Atmospheric Modeling System (RAMS) for the year 2011. The two forecasts differ only for the horizontal resolution of the RAMS model, which is $3 \mathrm{~km}(\mathrm{R} 3)$ and $12 \mathrm{~km}(\mathrm{R} 12)$, respectively. Both forecasts use the 12 UTC analysis/forecast cycle issued by the European Centre for Medium range Weather Forecast (ECMWF) as initial and boundary conditions.

As an additional comparison, the results of R3 and R12 are compared with those of the ECMWF Integrated Forecasting System (IFS), whose horizontal resolution over Central Italy is about $25 \mathrm{~km}$ at the time considered in this paper.

Because wind observations were not available for the site, the power curve for the whole wind farm was derived from the ECMWF wind operational analyses available at 00:00, 06:00, 12:00 and 18:00 UTC for the years 2010 and 2011. Also, for R3 and R12, the RAMS model was used to refine the horizontal resolution of the ECMWF analyses by a two-years hindcast at 3 and $12 \mathrm{~km}$ horizontal resolution, respectively.

The R3 reduces the RMSE of the predicted wind power of the whole 2011 by $5 \%$ compared to R12, showing an impact of the meteorological model horizontal resolution in forecasting the wind power for the specific site.
\end{abstract}

\section{Introduction}

Wind farms power prediction is of great importance, since a good forecast allows better integration of the renewable energy in the grid. A suitable use of wind energy needs the setup of methodologies able to reduce the uncertainty of the wind resource. The prediction system is usually based on meteorological models e.g. Limited Area Models (LAM) (Pinson et al., 2007; Alessandrini et al., 2013; Holmgren et al., 2010). These models predict the wind speed and direction in the target region and, by a power curve or other meth- ods (Giebel et al., 2011), this output is converted to the wind power forecast for the wind farm. Hence, the quality of the power forecast at different forecasting ranges depends on the quality of the wind prediction over the area of the wind power plant.

This paper shows the wind power prediction for a wind farm in Central Italy, starting from wind velocity forecast of the Regional Atmospheric Modeling System (RAMS; Cotton et al., 2003). In Italy, wind farms are usually located in complex terrain, where wind prediction is more difficult than in flat orography (Giebel et al., 2011). In these conditions the 


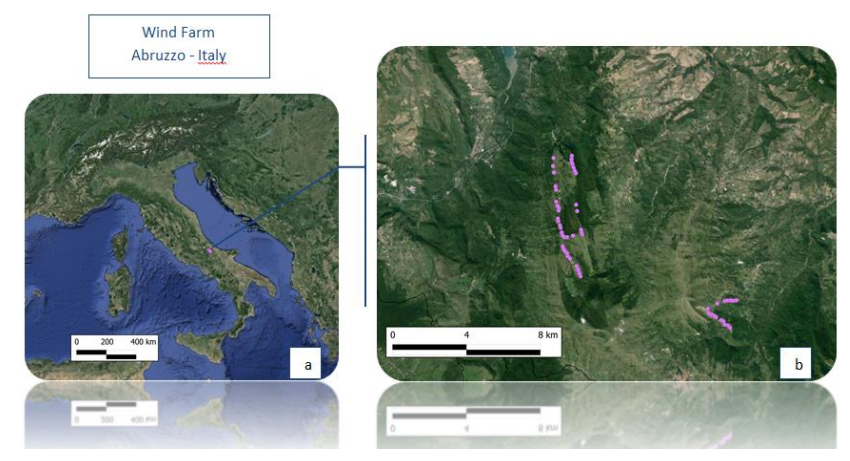

Figure 1. (a) Wind farm in Abruzzo (Central Italy), and (b) turbines layout.

horizontal resolution of LAMs has an important role and we discuss this point by comparing two $48 \mathrm{~h}$ wind power forecasts for the whole year 2011, using two wind forecasts at 3 (R3) and $12 \mathrm{~km}$ (R12) horizontal resolutions.

For completeness the wind power forecasts using the winds of R3 and R12 are compared with that issued using the winds of the ECMWF IFS 12:00 UTC analysis/forecast cycle. This cycle also gives the initial and dynamic boundary conditions for the R3 and R 12 forecasts. It is important to note that, while the differences between R 3 and $\mathrm{R} 12$ are only caused by their different horizontal resolution, the differences between IFS and RAMS forecasts are not only due to the horizontal resolution of the models, but also to their different physical and dynamical parameterizations, as well as to their different numerical coding.

Because of the natural variability of the Mediterranean climate, results are shown seasonally. Moreover, a case study is considered to better focus on the differences found for the models, while statistics are considered for 14 cases.

\section{Data and methodology}

The wind farm considered in this study is located in a complex orographic area in the Abruzzo region, Central Italy. The wind farm has wind turbines in 6 different zones away few kilometers each other. There are different kinds of turbines, with capacity of $0.6 \mathrm{MW}$ (Fig. 1).

The wind power prediction of this study can be divided in two-steps: (a) finding a power curve for the whole wind farm, and; (b) using the wind forecast of R3 and R12 and the corresponding power curve of the step (a) to issue the power forecast. While two years of data (2010-2011) were used for step (a), the power forecast is for 2011 only.

For the step (a) wind measurements were not available for the period considered, so we used meteorological analyses at 00:00, 06:00, 12:00 and 18:00 UTC to derive the wind in correspondence of the wind farm. Moreover, because we want to assess the impact of the horizontal resolution on the wind power forecast, two different dynamical downscaling

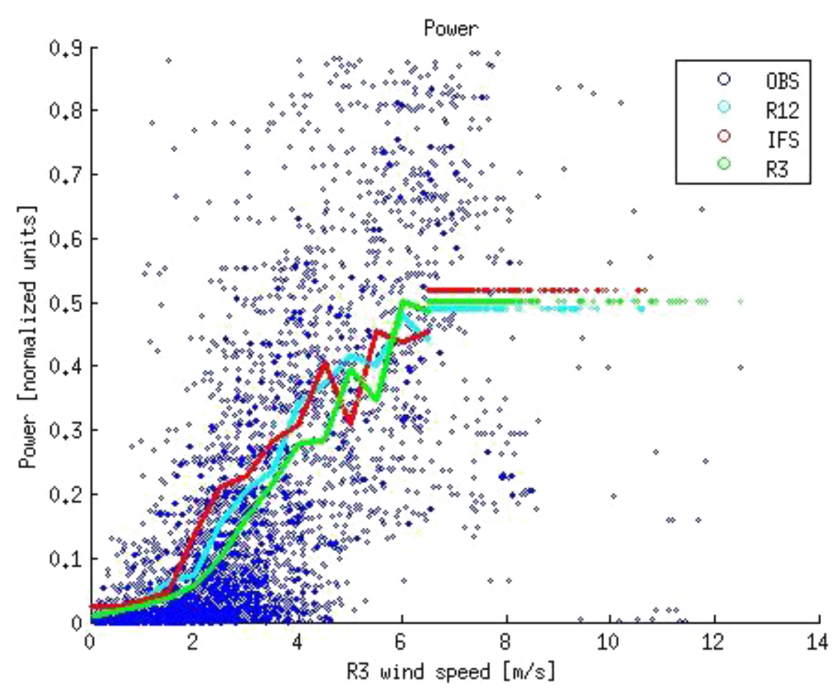

Figure 2. The power curve for R3, R12 and IFS. Blue diamonds show the pairs (wind, power) for the R3 case. R12 and IFS (wind, power) pairs are not shown for clarity.

(hindcast) were produced by R3 and R12, i.e. at 3 and $12 \mathrm{~km}$ horizontal resolution, respectively. Initial and boundary conditions of the R3 and R12 hindcasts are derived from the ECMWF operational analyses.

The R3 and R12 models share the same physical and dynamical parameterizations, which are as in Federico (2011), the only differences being their grids and horizontal resolutions. The R3 model uses two two-ways nested grids: the first grid has a horizontal resolution of $12 \mathrm{~km}$ and covers the Central part of the Mediterranean Basin, while the second grid extends over Central Italy with $3 \mathrm{~km}$ horizontal resolution. The R12 model uses only the first grid of the R3 model.

The surface wind speed of the RAMS hindcasts, as well as that of IFS, were bi-linearly interpolated to the position of the wind farm $\left(14.500^{\circ} \mathrm{E}, 41.875^{\circ} \mathrm{N}\right)$ at 00:00, 06:00, 12:00 and 18:00 UTC for each day and these values were used, with the corresponding values of the observed power produced by the wind farm, to find the power curve of the whole wind farm (Fig. 2).

To fit the data, the wind speed sample has been divided in bins $0.5 \mathrm{~m} \mathrm{~s}^{-1}$ wide; for each bin, we computed a fitting power by minimizing the variance between the power values inside the bin and the fitting power.

In addition to the large scatter of the data of Fig. 2, which is a common feature of all models considered in this paper and is, at least in part, caused by the lack of wind observations, it is noticed that IFS and R12 power curves lie above that of R3 for wind speeds in the range $2.0-4.5 \mathrm{~m} \mathrm{~s}^{-1}$. Stated in other terms, the power predicted by IFS and R12 is larger than that of R3, for the same velocity forecast in the range $2.0-4.5 \mathrm{~m} \mathrm{~s}^{-1}$.

It is also noticed that there are three different values of the power plateau for wind speed larger than $6.5 \mathrm{~m} \mathrm{~s}^{-1}$. This 
Table 1. Bias (BIA), mean absolute error (MAE), RMSE, coefficient of determination $\left(r^{2}\right)$ and skill score (SKILL) compared to the $3 \mathrm{~h}$ (first number of the cell) and $9 \mathrm{~h}$ (second number of the cell) persistence forecast for the wind power. P3 and P9 are the three and nine hours persistence forecast.

\begin{tabular}{|c|c|c|c|c|c|c|}
\hline & Statistics & R3 & $\mathrm{R} 12$ & IFS & P3 & P9 \\
\hline \multirow[t]{5}{*}{ Winter } & BIA (W) & 4112 & 4055 & 3256 & -9 & 4 \\
\hline & MAE (W) & 12236 & 12884 & 13555 & 7988 & 13981 \\
\hline & RMSE (W) & 16473 & 17122 & 18057 & 12706 & 20444 \\
\hline & $r^{2}$ & 0.45 & 0.39 & 0.32 & 0.66 & 0.26 \\
\hline & SKILL (\%) & $-30 ; 19$ & $-35 ; 16$ & $-42 ; 12$ & - & - \\
\hline \multirow[t]{5}{*}{ Spring } & BIA (W) & -1253 & -1826 & -547 & 17 & 3 \\
\hline & $\operatorname{MAE}(\mathrm{W})$ & 10383 & 11606 & 11552 & 7670 & 12965 \\
\hline & RMSE (W) & 14103 & 15589 & 15663 & 12624 & 19695 \\
\hline & $r^{2}$ & 0.63 & 0.55 & 0.54 & 0.72 & 0.40 \\
\hline & SKILL (\%) & $-12 ; 28$ & $-23 ; 21$ & $-24 ; 20$ & - & - \\
\hline \multirow[t]{5}{*}{ Summer } & BIA (W) & -1113 & -41 & -2856 & -2 & 20 \\
\hline & $\operatorname{MAE}(\mathrm{W})$ & 10616 & 11434 & 11508 & 8502 & 12986 \\
\hline & RMSE (W) & 16790 & 17182 & 17705 & 15634 & 22500 \\
\hline & $r^{2}$ & 0.34 & 0.30 & 0.29 & 0.51 & 0.16 \\
\hline & SKILL (\%) & $-7 ; 25$ & $-10 ; 24$ & $-11 ; 23$ & - & - \\
\hline \multirow[t]{5}{*}{ Fall } & BIA (W) & -2512 & -2574 & -2856 & 4 & 8 \\
\hline & MAE (W) & 9691 & 10597 & 11508 & 6476 & 11379 \\
\hline & RMSE (W) & 14845 & 15857 & 17705 & 13163 & 21301 \\
\hline & $r^{2}$ & 0.79 & 0.75 & 0.62 & 0.77 & 0.46 \\
\hline & SKILL (\%) & $-13 ; 30$ & $-20 ; 25$ & $-34 ; 17$ & - & - \\
\hline \multirow[t]{5}{*}{ Year } & BIA (W) & -209 & -119 & 278 & 2 & 9 \\
\hline & MAE (W) & 10726 & 11627 & 12187 & 7658 & 12825 \\
\hline & RMSE (W) & 15578 & 16445 & 17201 & 13581 & 21001 \\
\hline & $r^{2}$ & 0.54 & 0.49 & 0.44 & 0.68 & 0.34 \\
\hline & SKILL (\%) & $-15 ; 26$ & $-21 ; 22$ & $-27 ; 18$ & - & - \\
\hline
\end{tabular}

arises because the plateau is computed as the average of the observed power for wind speeds larger than $6.5 \mathrm{~m} \mathrm{~s}^{-1}$ for each model. The number of speeds larger than $6.5 \mathrm{~m} \mathrm{~s}^{-1}$ varies for R3, R12 and IFS giving the different values of the plateau shown in Fig. 2. It is noted, however, that the plateau difference among the models has a small impact on the results of this paper (see next section).

For the step (b), a one-year forecast (2011) of R3 and R12 for the following $48 \mathrm{~h}$ was made. Initial and boundary conditions were derived from the ECMWF-IFS 12 UTC operational analysis/forecast cycle. The surface wind speeds of the R3, R12 and IFS forecasts were interpolated to the position of the wind farm $\left(14.500^{\circ} \mathrm{E}, 41.875^{\circ} \mathrm{N}\right)$ and used to produce the power forecast by employing the corresponding power curve of Fig. 2. As stated in the previous section the differences between R3/R12 and IFS are not only caused by their different spatial resolutions.

Before concluding this section it is noted that both steps, (a) and (b), are important for the power forecast issued by each model. Indeed, while the quality of the wind forecast directly impacts the power forecast in the step (b), each model uses its own power curve, whose quality is in turn determined by the ability of each model to simulate the wind for the specific site.

\section{Results}

Considering the comparison between R3 and R12 (Table 1), it is noticed that the Bias is similar for all season but summer, when R12 performs better than R3. The Bias is positive in winter for both R3 and R12, while it is negative for other seasons as well as for the whole year $(-209 \mathrm{~W}$ for R3 and $-119 \mathrm{~W}$ for R12).

The MAE and RMSE show that R3 scores better than R12. Focusing on the RMSE, there is a reduction of $5 \%$ of the RMSE for the whole year for R3 compared to R12. The largest RMSE reduction occurs in spring $(10 \%)$, while the lowest in summer $(2 \%)$. This shows the importance of the seasonal forcing on the results.

The coefficient of determination $\left(r^{2}\right)$ also shows that R3 performs better than $\mathrm{R} 12$ because the correlation between the predicted and observed power is larger for R3. This occurs for all seasons as well as for the whole year. It is also noticed 


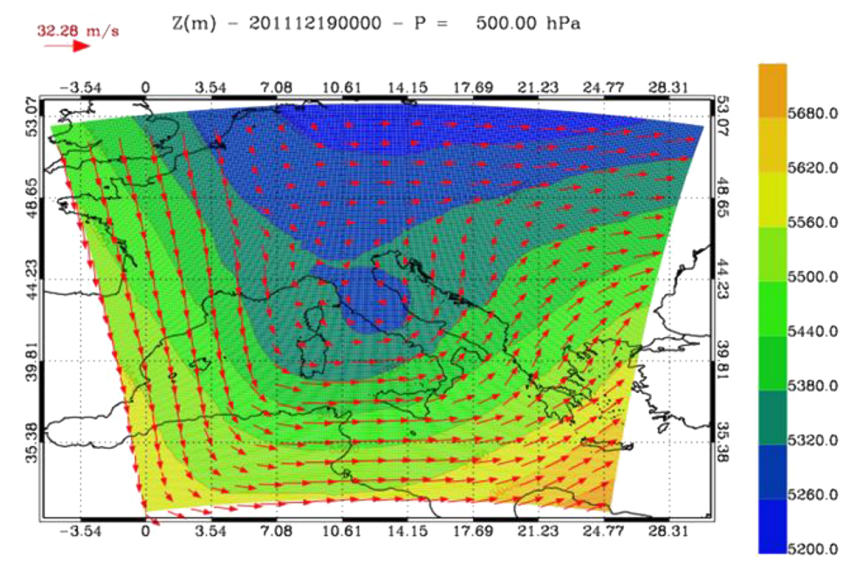

Figure 3. Geopotential height and wind vectors at $500 \mathrm{hPa}$ on 19 December 2011 at 00:00 UTC. A cut-off $(5320 \mathrm{~m})$ is apparent over central Italy.

the decrease of the coefficient of determination in summer compared to other seasons, showing the difficulty of forecasting the wind power for the site when local circulations play a major role.

Another statistic shown in Table 1 is the skill of the model compared to the 3 and $9 \mathrm{~h}$ persistence forecast. The skill is computed for RMSE, i.e.:

SKILL $=100 \frac{\text { RMSE }_{P}-\text { RMSEF}_{F}}{\text { RMSEP }_{P}}$.

In Eq. (1) the RMSE is the RMSE of the persistence, while $\mathrm{RMSE}_{\mathrm{F}}$ is the RMSE of the forecast. A positive value of the skill means an improvement of the forecast compared to persistence.

The results of Table 1 show that both R3 and R12 have skill compared to the $9 \mathrm{~h}$ persistence, while the $3 \mathrm{~h}$ persistence performs better than the RAMS forecast. This is true for all seasons and for the whole year, showing a stable result. Comparing the results of R3 and R12 we notice the larger skill for R3, showing again the positive impact of the model horizontal resolution on the power forecast for the specific site.

It is also noticed that the statistics of Table 1 were recomputed assuming a unique power plateau in the power curve (Fig. 2) for all models. This value was, in turn, that of R3, R12, IFS and the average of the three. However, the results were similar to that of Table 1, computed assuming for each model its own value of the plateau. So, the statistics of Table 1 are not sensitive to the choice of the plateau value.

Considering the results for IFS, it is noticed that IFS has the largest RMSE and the lowest coefficient of determination among the models compared in this work. This is true for all seasons and for the whole year. Considering the whole year, the RMSE for R3 is $10 \%$ lower compared to IFS, while the coefficient of determination $\left(r^{2}\right)$ is 0.54 for R3 and 0.44 for IFS. The IFS has skill compared to the $9 \mathrm{~h}$ persistence, while the $3 \mathrm{~h}$ persistence performs better, similarly to the re-

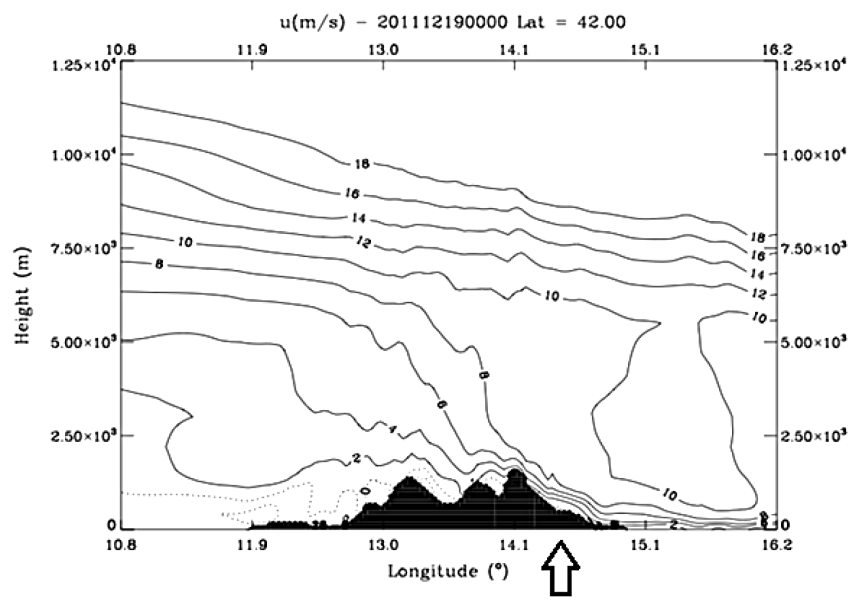

Figure 4. Vertical cross section at $42^{\circ} \mathrm{N}$ of the zonal wind showing the deep gravity wave generated by the Apennines. The arrow shows the approximate longitude of the wind farm.

sult found for R3 and R12. However, the IFS skill is lower than those of R12 and R3.

We note that the skill of the model compared to the $6 \mathrm{~h}$ persistence (not shown) is in between the skills compared to the 3 and $9 \mathrm{~h}$ persistence. In particular R3 and R12 have skill compared to the $6 \mathrm{~h}$ persistence for all seasons as well as for the whole year, while the IFS doesn't have skill compared to the $6 \mathrm{~h}$ persistence in winter. The values of the R3 and R12 skills compared to the $6 \mathrm{~h}$ persistence are often below $10 \%$.

To show a case study for which the forecast resolution has an important role, we focus on the period from 15 to 20 December 2011.

This period was characterized by the passage of cyclones over the Central Mediterranean Basin. On 19 December 2011 the RAMS forecast at 00:00 UTC shows the passage of one of these cyclones over Central Italy (Fig. 3). The cyclone evolved in a cut-off at $500 \mathrm{hPa}$ and air masses crossed the Central Italy from west to east. In these conditions, the orography of the Apennines can generate deep gravity waves as shown by the zonal velocity of Fig. 4 .

The linear theory of standing gravity waves predicts an increase of the wind speed on the lee of the orographic barrier, consistently with the results of Fig. 4. However, nonlinear effects become significant in a multilayered atmosphere even at small values of the Froude number $(F r=N h / U$, where $U$ is the mean undisturbed flow, $h$ is the height of the orographic barrier and $N$ is the buoyancy frequency of the atmosphere), and the behavior of the interaction between the flow and the orography is more complex than that depicted by the linear theory (Durran, 1986).

The characteristics of the interaction between the atmospheric flow and the orography can be described considering the value of the Froude number. If $F r$ is larger than 1 the flow is referred to as supercritical, if the Froude number is less than 1 the flow is subcritical. In everywhere (i.e. before 

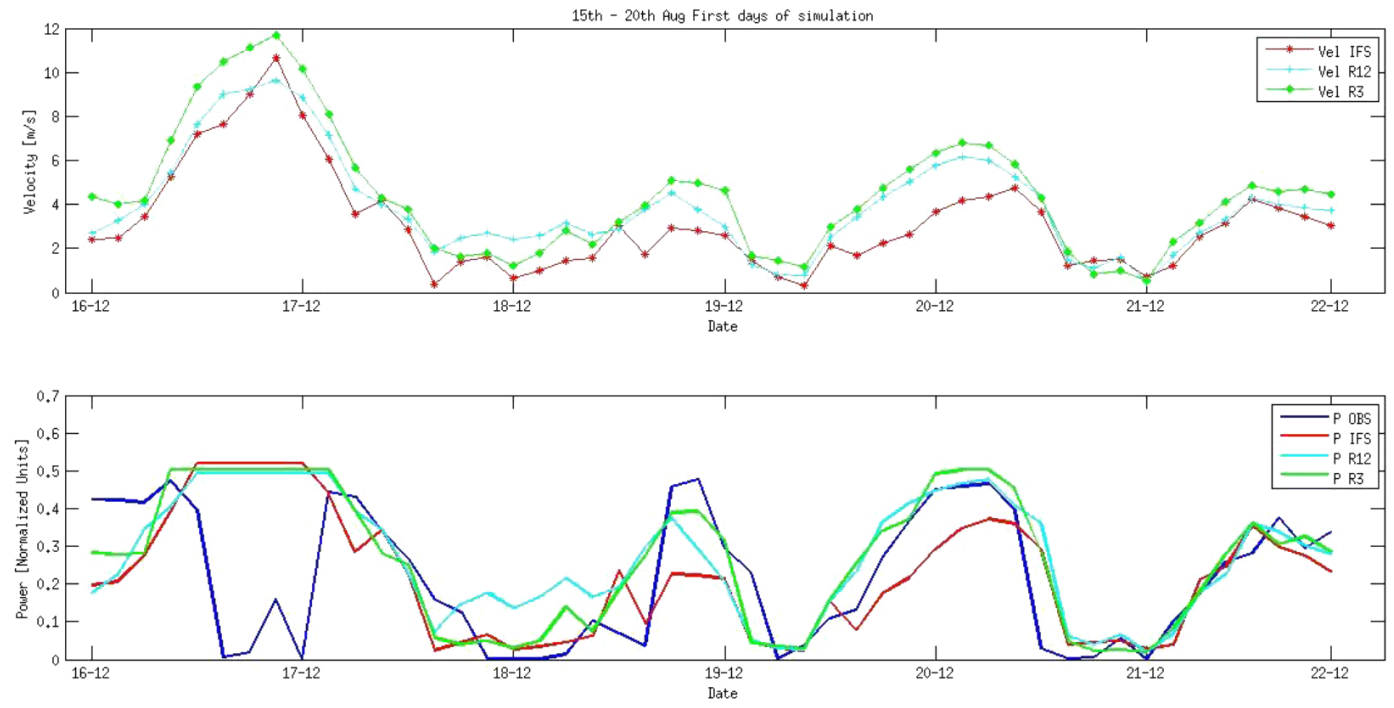

Figure 5. Upper panel: the wind velocity forecasts for the period 15-20 December 2011 (R3 is the green curve, R12 is the cyan curve and IFS is the red curve). Lower panel: comparison between the observed (blue curve), R3 (green curve), R12 (cyan curve) and IFS (red curve) wind powers for the same period of the upper panel. Note that the power forecast reached the plateau of Fig. 2, which differs for each model, for part of 16 and 17 December 2011 (wind speeds larger than $6.5 \mathrm{~m} \mathrm{~s}^{-1}$ ).

and after the topography peak) supercritical flow, the wind speed has a maximum on the lee side of the orographic barrier, whose position depends on the value of the static stability of the atmosphere, on the value of the undisturbed flow velocity and on the height and shape of the orography. In supercritical flow high winds develop on the lee of the mountain. In everywhere subcritical flow the velocity has a maximum over the mountain crest.

The largest winds on the leeside of the orographic barrier occur when there is a transition from subcritical to supercritical flow at the top of the orography. This situation occurs in windstorms and, roughly speaking, the flow recovers its subcritical state near the bottom of the orographic barrier with an hydraulic jump (Durran, 1986). Wave breaking also plays an important role in windstorms.

Figure 4 shows the development of a deep gravity wave and intense winds on the lee of the orographic barrier, where the wind farm is located, suggesting the passage to supercritical flow on the lee of the mountains. In these conditions, the horizontal resolution of the model has an important role in the forecast of the evolving cyclone and of the wind speeds, specifically at lower atmospheric levels where wind turbines are located. The interaction between air-masses and orography is simulated in more detail for increasing horizontal resolutions and differences arise between R3 and R12. For the specific case study we found that $\mathrm{R} 3$ velocities are larger than those of R12, even if it is not always the case, as shown for part of the 17 and 18 December (Fig. 5a). In general, the velocities simulated by IFS are smaller than those of R3 and R12.
Figure $5 \mathrm{~b}$ shows the comparison among wind power calculated for R3, R12 and IFS and the observed values in the period considered. All forecasts show a similar behavior; nevertheless the R3 follows more closely the observations, especially for 18 December. The IFS underestimates the observed power as a consequence of the lower wind speed simulated. We also note that the velocities forecast by all models are larger than $6.5 \mathrm{~m} \mathrm{~s}^{-1}$ for most of 16 and part of the 17 December. The power forecast reaches the plateau for each model, causing the (small) difference of the power forecast of Fig. 5.

The situation shown in Figs. 3-5 is not uncommon in Central Italy. To better assess the importance of the interaction between the large-scale systems and the local orography, we considered the cases when, for the whole $48 \mathrm{~h}$ of forecast, R3 has a $10 \%$ RMSE improvement compared to R12. For these cases we also require that the averaged observed power for the two forecast days is larger than $10 \mathrm{~kW}$ to exclude cases when the wind is low, the power production small, and the behavior of the (small) RMSEs becomes erratic.

We found a total of 49 days and, among them, 23 (roughly $50 \%$ of the cases) were associated with synoptic scale disturbances acting over Central Italy. The RMSE for those cases is shown in Table 2, with a short description of the synoptic environment. For some cases the situation is similar to that of Figs. 3-5, with a cyclone crossing Central Italy (for example the 15 May 2011), for other cases the cyclone did not cross Central Italy, nevertheless its action extended over the target area.

The numbers above show that the interaction between the large scale flow and the Apennines orography is a key feature 
Table 2. Selected events for which the performance of R3 is better than R12 (plain text). A short synoptic description of the events is shows in the last column. Each cell for R3, R12 and IFS shows the value of the RMSE ([W], first value) and of the coefficient of determination ( $r^{2}$, second value). In bold two cases when R12 is better than R3 are shown. The number in parenthesis in the first column shows the consecutive days of better/worse R3 performance compared to R12. For cases lasting more than one day, statistics are shown for the first day of the event.

\begin{tabular}{|c|c|c|c|c|}
\hline Date & $\mathrm{R} 3$ & $\mathrm{R} 12$ & IFS & Synoptic description \\
\hline $14 \operatorname{Jan} 2011(2)$ & $15879 \mathrm{~W}, 0.42$ & $18236 \mathrm{~W}, 0.19$ & $18032 \mathrm{~W} ; 0.21$ & Wave trough over the Balkans \\
\hline 13 Feb 2011 (3) & $16500 \mathrm{~W}, 0.89$ & $19032 \mathrm{~W}, 0.84$ & $22250 \mathrm{~W} ; 0.78$ & $\begin{array}{l}\text { Cyclone developing on the west } \\
\text { Mediterranean (Lyon Gulf) }\end{array}$ \\
\hline 18 Feb 2011 & $15173 \mathrm{~W}, 0.79$ & $19092 \mathrm{~W}, 0.71$ & $20116 \mathrm{~W} ; 0.68$ & $\begin{array}{l}\text { Influence of the cyclone of } 20110215 \\
\text { (above row) while evolving toward the } \\
\text { South-East }\end{array}$ \\
\hline 15 Mar 2011 (3) & $29059 \mathrm{~W}, 0.60$ & $33894 \mathrm{~W}, 0.50$ & $36726 \mathrm{~W} ; 0.19$ & $\begin{array}{l}\text { Cyclone developed over the western } \\
\text { Mediterranean and crossing central } \\
\text { Italy }\end{array}$ \\
\hline 15 May 2011 (3) & $16776 \mathrm{~W}, 0.83$ & $19722 \mathrm{~W}, 0.73$ & $18890 \mathrm{~W} ; 0.76$ & $\begin{array}{l}\text { Cyclone (developed on the lee of the } \\
\text { western Alps) crossing Central Italy }\end{array}$ \\
\hline 18 Jun 2011 & $13646 \mathrm{~W}, 0.78$ & $16642 \mathrm{~W}, 0.63$ & $16061 \mathrm{~W} ; 0.69$ & Wave trough crossing central Europe \\
\hline 27 Jul 2011 & $18260 \mathrm{~W}, 0.89$ & $21379 \mathrm{~W}, 0.76$ & $23422 \mathrm{~W} ; 0.51$ & Wave trough crossing central Europe \\
\hline 20 Sep $2011(2)$ & $12487 \mathrm{~W}, 0.90$ & $15106 \mathrm{~W}, 0.82$ & $15382 \mathrm{~W} ; 0.75$ & $\begin{array}{l}\text { Cyclone (developed on the lee of the } \\
\text { Alps) crossing Southern Italy }\end{array}$ \\
\hline 18 Oct $2011(2)$ & $24322 \mathrm{~W}, 0.83$ & $27366 \mathrm{~W}, 0.78$ & $29811 \mathrm{~W} ; 0.66$ & Cyclone on the lee of the Eastern Alps \\
\hline 22 Nov 2011 (2) & $13952 \mathrm{~W}, 0.25$ & $16357 \mathrm{~W}, 0.21$ & $15923 \mathrm{~W}, 0.01$ & $\begin{array}{l}\text { Cyclone evolving on the Western } \\
\text { Mediterranean }\end{array}$ \\
\hline 17 Dec 2011 & $10211 \mathrm{~W}, 0.66$ & $13747 \mathrm{~W}, 0.39$ & $12635 \mathrm{~W} ; 0.54$ & $\begin{array}{l}\text { Cyclone developing on the lee of the } \\
\text { Alps and crossing Central Italy }\end{array}$ \\
\hline $18 \operatorname{Dec} 2011(2)$ & $12275 \mathrm{~W}, 0.67$ & $14098 \mathrm{~W}, 0.55$ & $14265 \mathrm{~W} ; 0.46$ & $\begin{array}{l}\text { Cyclone developing on the lee of the } \\
\text { Alps and crossing Central Italy }\end{array}$ \\
\hline 20 Jul $2011(3)$ & $19680 \mathrm{~W}, 0.23$ & $17606 \mathrm{~W}, 0.34$ & 21164 W; 0.03 & Cyclone over the Central Europe \\
\hline 24 Dec 2011 & $12856 \mathrm{~W}, 0.76$ & $9340 \mathrm{~W}, 0.73$ & $12312 \mathrm{~W} ; 0.56$ & $\begin{array}{l}\text { Cyclone developing on the lee of the } \\
\text { Alps and crossing Central Italy }\end{array}$ \\
\hline
\end{tabular}

for the successful forecast of the wind power for the case considered, as the higher resolution of the forecast resolves in more detail this interaction.

It is important to highlight that the R3 is not always the best forecast. The impact of the model horizontal resolution on the wind speed forecast has been studied by several authors (for example Möhrlen et al., 2002; Rife and Davies, 2005; Hashimoto et al., 2007; see Giebel et al., 2011, for a review). In several of these studies it is found that the increase of the model horizontal resolution improves the forecast of the intensity and gradient of the wind speed, so that the wind field resembles more closely the reality at higher resolution. Nevertheless, traditional verification metrics, as those used in this paper, often improve slightly or even show worse performance for higher horizontal resolution because they penalize forecasts with small temporal or spatial errors (phase errors). In other terms, because the wind and its gradient are, in gen- eral, more intense at higher horizontal resolutions, the phase error is amplified, and this penalize the traditional scores of comparatively higher resolution forecasts.

For the forecast considered in this paper, we found 8 days when the RMSE of R12 had a $10 \%$ improvement compared to R3. Also for these cases we required that the averaged observed power for the whole forecast is larger than $10 \mathrm{~kW}$. For five of these days a clear synoptic system was acting over the area (Table 2, cases in bold).

For the two days of July 2011 the R3 model underestimates the observed power (the R3 bias is $-8115 \mathrm{~W}$, while the $\mathrm{R} 12$ bias is $-4444 \mathrm{~W}$ ). This is caused by the slower winds simulated by R3 compared to R12. This error is amplified by the power curves of R3 and R12 (Fig. 2) for wind speed in the range $2-4.5 \mathrm{~m} \mathrm{~s}^{-1}$.

For the case of December 2011, R3 simulates too strong winds (the bias of the R3 power forecast is $10803 \mathrm{~W}$, while 


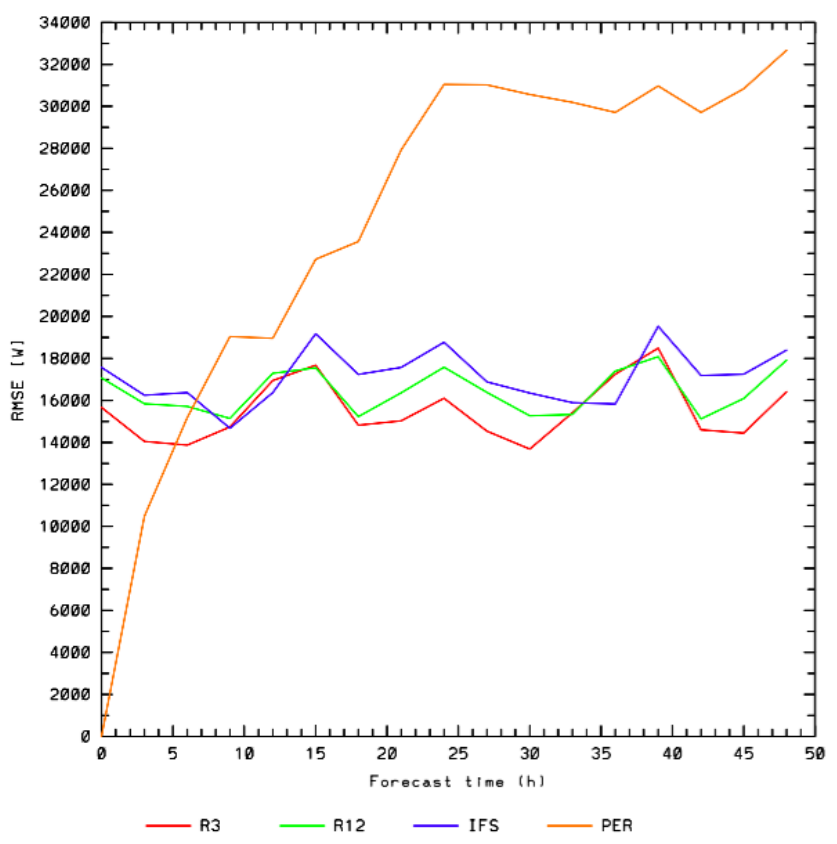

Figure 6. RMSE for R3 (red), R12 (green), IFS (blue) and PER (orange) as a function of the forecasting time for the first and second forecast days.

that of R12 is $8505 \mathrm{~W}$ ). The too strong wind speeds are simulated as a consequence of a cyclone that was located over central Italy on 24 December 2011. Likely, the position and/or the intensity of the cyclone are not well simulated by RAMS for this case and the error is amplified by R3 compared to R12.

Another point considered in this paper is the performance of the forecast with forecasting time. Figure 6 shows the RMSE for the R3, R12, IFS and persistence (PER) forecasts every three-hours for the two forecast days. It is apparent that the RAMS and IFS RMSEs do not increase considerably with forecasting time. This is confirmed by the RMSEs for the first and second day forecasts. Using the triple (RMSE_R3, RMSE_R12, RMSE_IFS) we have, respectively, for the first and second forecast day (15490, $16437,17139 \mathrm{~W})$ and $(15842,16665,17399 \mathrm{~W})$. So, for the second forecast day, we have an increase of the forecast error below $5 \%$ of the RMSE for the first forecast day.

In a recent paper on the performance of the RAMS forecast for Southern Italy, run using a configuration similar to that used in this paper for the year 2013, Tiriolo et al. (2015) show that the RMSE for the wind and for the third forecast day increases by less than $10 \%$ of its value at the initial time, finding a small increase of the error with forecasting time. Even if the power law is not linear with the wind, this paper confirms the small increase of the error with forecasting time for the wind power too.

\section{Conclusions}

This paper shows the $48 \mathrm{~h}$ wind power forecast for a wind farm located in complex terrain in Central Italy and focuses on the impact of the horizontal resolution of the wind forecast on the power prediction.

The power forecast is divided in two steps: (a) finding a power curve for the whole wind farm, and; (b) applying the power curve along with the wind forecast to issue the power forecast. We evaluate the performance of two models, R3 and R12, differing only for their horizontal resolutions (3 and $12 \mathrm{~km}$, respectively) and grids. Moreover, as a further comparison, we show the performance of the IFS model of ECWMF.

Wind observations were not available at the site for the period considered, and ECMWF-IFS operational analyses were used to compute the power law for the whole wind farm. To increase the horizontal resolution of the wind field, in order to better account for the local orography, a two-years hindcast of the RAMS model was made at 3 and $12 \mathrm{~km}$ horizontal resolution, and the power law was computed using the surface wind speed of the hindcast as well as the analyses of the ECMWF-IFS. In this way, each model has its own power curve, which is a key feature of the power forecast.

The results show the importance of the horizontal resolution for the power prediction. Considering the whole year, the comparison between the power forecast of R3 and that of R12 shows a RMSE reduction of about $5 \%$ when using the higher resolution. The improvement, however, has a noticeable seasonal variability, reaching the maximum value (10\%) in spring and the lowest value (2\%) in summer.

The coefficient of determination is larger for R3 compared to R12 for all seasons and for the whole year, confirming the importance of the horizontal resolution of the forecast, for the specific site.

The comparison with the persistence forecast shows that $\mathrm{R} 3$ and R12 forecasts are better than the 6 and $9 \mathrm{~h}$ persistence, while they are worse than the $3 \mathrm{~h}$ persistence. Moreover, the $\mathrm{R} 3$ skill is better than that of R12.

The IFS forecast has the worst performance among all models considered. While the horizontal resolution of the IFS forecast is about $25 \mathrm{~km}$ for the period and area considered, it is noted that the differences between the RAMS and IFS forecasts are not only attributable to the different resolutions of the models. Several other factors as the difference in numerical and physical parameterizations contribute.

A closer investigation of the model performance for different cases shows the importance of the interaction between the large-scale flow and the orography. This interaction is resolved in more detail at finer horizontal resolution that give, in general, better results. There are occasions, however, when the position/intensity of meteorological systems are not well represented in space and/or time. For these cases the higher resolution may amplify the phase errors that penalizing traditional scores. 
Acknowledgements. This work was carried out during a model benchmark exercise within the COST Action ES1002 WIRE (Weather Intelligence for Renewable Energies). It was also supported by the projects PON04a2_E Sinergreen-ResNovae - "Smart Energy Master for the energetic government of the territory" and PONa3_00363 "High Technology Infrastructure for Climate and Environment Monitoring" founded by Italian Ministry of University and Research (MIUR) PON 2007-2013. The ECMWF and CNMCA - "Centro Nazionale di Meteorologia e Climatologia Aeronautica" are acknowledged for giving the access to the analyses and forecasts of the IFS. We are grateful to Edison Energie Speciali Spa for the wind farm power data.

Both reviewers are acknowledged for their useful and constructive comments, which improved the quality of the paper.

Edited by: S.-E. Gryning

Reviewed by: two anonymous referees

\section{References}

Alessandrini, S., Sperati, S., and Pinson, P.: A comparison between the ECMWF and COSMO Ensemble Prediction Systems applied to short-term wind power forecasting on real data, Appl. Energy, 107, 271-280, 2013.

Cotton, W. R., Pielke Sr., R. A., Walko, R. L., Liston, G. E., Tremback, C. J., Jiang, H., McAnelly, R. L., Harrington, J. Y., Nicholls, M. E., Carrio, G. G., and McFadden, J. P. : RAMS 2001: Current satus and future directions, Meteor. Atmos., 82, 5-29, 2003.

Durran, D. R.: Another look at downslope wind storm. Part I: The development of analogs to supercritical flows in an infinitely deep, continuously stratified flow, J. Atmos. Sci., 43, 2527-2543, 1986.

Federico, S.: Verification of surface minimum, mean, and maximum temperature forecasts in Calabria for summer 2008, Nat. Hazards Earth Syst. Sci., 11, 487-500, doi:10.5194/nhess-11-487-2011, 2011.
Giebel, G., Brownsword, R., Kariniotakis, G., Denhard, M., and Draxl, C.: The State of the Art in Short-Term Prediction of Wind Power: A Literature Overview, Deliverable Report D1.1 of the Anemos project (ENK5-CT-200200665), available at http://www.anemos-plus.eu/images/pubs/ deliverables/aplus.deliverable_d1.2.stp_sota_v1.1.pdf, last access: April 2015.

Hashimoto, A., Hattori, Y., Kadokura, S., Wada, K., Sugimoto, S., Hirakuchi, H., and Tanaka, N.: Effects Of Numerical Models On Local-Wind Forecasts Over A Complex Terrain with Wind Farm Prediction Model, Proceedings of the European Wind Energy Conference, Milano (IT), 7-10 May 2007.

Holmgren, E., Siebert, N., and Kariniotakis, G.: Wind Power Prediction Risk Indices Based on Numerical Weather Prediction Ensembles, Oral presentation at EWEC 2010 Conference, Warsaw, Poland, 20-23 April 2010.

Möhrlen, C., Jørgensen, J. U., and McKeogh, E. J.: Power predictions in Complex Terrain with an operational Numerical Weather Prediction Model in Ireland including Ensemble Prediction, Proc. World Wind Energy Conference "Clean Power for the World", Berlin, Germany, 2002

Pinson, P., Nielsen, H. Aa., Møller, J. K., Madsen, H., and Kariniotakis, G.: Nonparametric probabilistic forecasts of wind power: required properties and evaluation, Wind Energy, 10, 497-516, 2007.

Rife, D. L. and Davis, C. A.: Verification of Temporal Variations in Mesoscale Numerical Wind Forecasts, Mon. Weather Rev., 133, 3368-3381, 2005.

Tiriolo, L., Torcasio, R. C., Montesanti, S., and Federico, S.: Verification of a real time weather forecasting system in southern Italy, Adv. Meteorol., 2015, 14 pp., doi:10.1155/2015/758250, 2015 